\section{Delayed response learning by cage-reared normal and prefrontal cats*}

\author{
GUNILLA WIKMARK† and J. M. WARREN \\ The Pennsylvania State University, University Park, Pa. 16802
}

Twelve intact cats and eight with lesions in the prefrontal cortex were trained on two-choice locomotor delayed response with auditory cues. The groups did not differ significantly on predelay, $0-$, and 5 -sec delays; eight controls, but no frontals, met criterion on 15 -sec delays $(p=.01)$. Prefrontal lesions impair the learning of delayed response but not as severely as is the case with adult rhesus monkeys. The cage-reared normal cats learned delayed response more slowly than Divac's (1968) trapped alley cats tested under almost identical conditions, confirming previous observations that cage-rearing interferes with some spatial learning capacities in cats.

The evidence regarding the effects of prefrontal ablations on delayed response (DR) performance by cats is equivocal and appears to suggest that retention is more severely affected than the capacity for postoperative learning. Warren (1964) found that cats with lesions in gyrus proreus were deficient in learning $D R$, but Thompson (1968) and Warren, Warren, \& Akert (1962) did not. Yet, cats with similar frontal lesions are consistently impaired in DR retention when tested in the Nencki testing situation (NTS) (Divac, 1968, 1969; Lawicka \& Konorski, 1961).

The rather contradictory findings of the learning and retention studies may simply reflect the sensitivity of the behavioral tests used. Thompson (1968) used a maze intended to incorporate several features of the NTS but only tested his cats on 0 -sec delays. The conflicting results of Warren (1964) and Warren, Warren, \& Akert (1962) were obtained in the Wisconsin General Test Apparatus (WGTA); learning by normal cats is much slower and more variable across individual $S$ s in the WGTA than in the NTS.

These considerations suggested that conclusive evidence of impairment in DR learning might be obtained from prefrontal preparations tested on 5and 15-sec delays in the NTS. The purpose of the present experiment was to test this hypothesis.

SUBJECTS

Twenty adult cats, 12 unoperated controls and 8 with lesions in gyrus proreus, were studied. All had previously been trained on visual discrimination problems, but none had been tested on DR or any task with auditory cues. One control (Fay) had been reared on a farm. All of the other

*This research was supported by Grant MH-04726 from the National Institute of Mental Health, U.S. Public Health Service. +Now at the University of Copenhagen.
Ss were born in the laboratory and were reared in $60 \times 60 \times 80 \mathrm{~cm}$ cages. of food deprivation and reinforced for correct responses with small cubes of pork kidney.

\section{APPARATUS AND PROCEDURE}

The apparatus, shaping, and training procedures were essentially identical with those described by Divac (1968). The apparatus is a rectangular enclosure $(77 \times 132 \mathrm{~cm})$ containing a central restraining cage and two feeders $180 \mathrm{deg}$ apart on the short sides of the rectangle. $S$ was adapted to the apparatus and shaped to approach the feeder, which emitted a continuous white noise. Formal training consisted of four successive phases. In predelay training, the cat was confined in the cage while the noise was presented for 3 sec and then released to approach the feeder identified by the continuing noise signal. All Ss were trained for at least 30 trials at this stage or longer if necessary to satisfy the criterion of eight correct responses in a single session of 10 trials. In delayed response testing, the noise was presented for $3 \mathrm{sec}$ only while the cat was in the cage, and 0,5 , or $15 \mathrm{sec}$ intervened between offset of the signal and release of $S$. The animals were trained 10 trials a day to a criterion of 27 correct in 30 trials on each delay. Training was terminated after 100 trials without reaching criterion, unless $\mathrm{S}$ made $75 \%$ correct responses on Trials 71-100, in which case it was allowed another 50 trials to satisfy the criterion.

The conditions for testing $D R$ in the NTS differ from those in the WGTA in the following major ways: (1) the signal is auditory, not visual; (2) the training method is indirect, not direct; (3) the response is locomotor, not manual; (4) the angular and absolute separation of the response alternative is much greater in the NTS than in the WGTA. The animals were tested under $20-23 \mathrm{~h}$
SURGERY AND HISTOLOGY

The cats were anesthetized with pentobarbital $(36 \mathrm{mg} / \mathrm{kg})$, and the lesions were made by subpial aspiration under aseptic conditions. Behavioral testing began on the 11th postoperative day. At sacrifice, the animals were perfused with saline and formalin and their brains removed, hardened, and embedded in albumin before being cut into 25 -micron frozen sections. Every fifth section through the lesion and potentially affected parts of the thalamus were stained with cresyl violet.

\section{RESULTS}

\section{Anatomy}

Representative cross sections of the hemispheres from the cats with the largest, smallest, and median lesions are shown in Fig. 1. Gyrus proreus was largely, but not completely, destroyed in all cases, and the lesion invaded the orbital and sigmoid gyri in three cats. Clear evidence of retrograde degenerative changes in the mediodorsal (MD) thalamic nucleus was observed only in the sections corresponding to frontal planes 8.5-10.5 in Jasper \& Ajmone-Marsan's (1960) atlas. The degeneration within the affected region was incomplete in all cases and ranged from relatively mild through near total cell loss in restricted foci of maximum degeneration; the amount of cell loss in anterior MD approximately paralleled the extent of the cortical lesion in individual cases. In agreement with Warren, Warren, \& Akert (1962), we did not observe any degeneration in the caudal portion of MD.

\section{Behavior}

The scores for the normal and frontal cats are presented in Table 1, with the frontals ordered from the smallest (Kanga) to largest (Imp) in respect to lesion size. The frontal group does not differ significantly from the controls in respect to trials or errors to criterion on predelay, 0 -, or 5 -sec delays. Fisher's exact probability test indicates, however, that the difference in the proportion of successful animals in the two groups on 15-sec delays is significant at the $5 \%$ level of confidence and that a significantly larger proportion of normal $(8 / 12)$ than frontal $(0 / 8)$ cats met criterion on all tasks $(p=.01)$. There was no significant relation between lesion size and errors on any delay.

The performance of 37 intact, trapped wild cats tested in the same apparatus with the same testing procedures is summarized at the bottom of Table 1. Divac's (1968, 1969) free-reared alley cats obviously mastered the four stages in training more quickly than our sample of laboratory-reared normals. Only two 
<smiles>C1CCC(=[V]2CCCC2)C1</smiles>

151

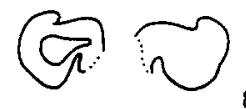

81

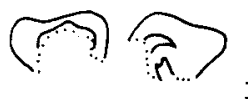

31

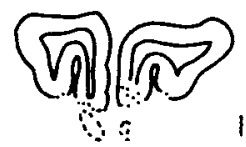

191

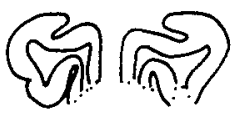

$13 \mid$

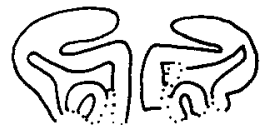

101

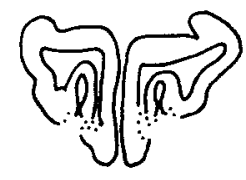

231
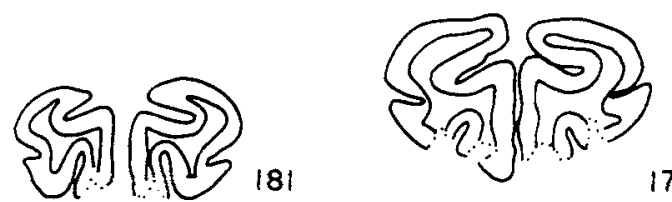

171

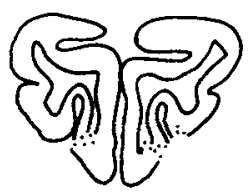

271

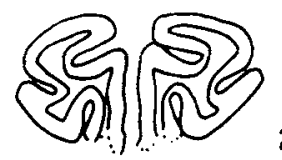

231

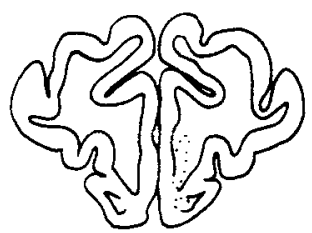

241

K

w

I they have always been tested under analogously favorable conditions. Several potentially important variables have now been varied in $D R$ experiments with cats: training method, length of delay, distance and angular separation of discriminanda, criterion response, and distraction during the delay period. And yet, no one has found the abolition of $D R$ capacity so frequently seen in frontal monkeys.

Experiments on delayed alternation reveal a complementary discrepancy between cats and monkeys. Some cats can relearn delayed alternation after undergoing frontal decortication in less than 100 trials in the NTS (Divac, in press). Monkeys with frontal lesions are much more severely impaired in relearning delayed alternation when tested in the WGTA, a maze, or a primate chair (Stamm, 1970).

Although they were trained under virtually identical conditions, most of our normals learned DR more slowly than Divac's (1968, 1969) animals, which were brought into the laboratory as adults. The only cats in the present experiment that learned as quickly as Divac's Ss were two animals that had been free to move about relatively large areas before $D R$ testing.

Many experiments with rodents indicate that animals reared in close confinement are inferior to $\mathrm{Ss}$ provided with access to open fields on tests of spatial orientation (Gluck \& Harlow, 1971). Comparable results cats in the present experiment fell within the range of Divac's animals. One was Fay, the cat whichhad grown up on a farm. The second, Edwin, had, unlike any of the other lab-reared cats, lived in a large outdoor pen since puberty.

\section{DISCUSSION}

Our hypothesis that frontal cats would be more profoundly impaired in learning DR in the NTS than in the WGTA was not confirmed. The results of this experiment were much the same as those reported by Warren (1964), who found that, although they were not impaired in learning 5-sec delays in the WGTA, frontal cats were significantly inferior to control animals under more demanding test conditions.

Divac \& Warren (1971) have argued that frontal lesions produce less severe defects on DR tasks in cats than in rhesus monkeys, since even cats which are significantly impaired in retention of DR in the NTS perform at substantially better than chance levels on early postoperative tests with 30-sec delays (Divac, 1968) and manifest considerable recovery of $D R$ proficiency during prolonged postoperative training (Lawicka \& Konorski, 1961). The subtotal impairment in $D R$ acquisition observed in the current series of frontal cases is quite compatible with this view.

Monkeys with frontal cortical ablations occasionally succeed on DR tasks presented under particularly favorable conditions (Divac \& Warren, 1971; Finan, 1942; Pinsker \& French, 1967). It is, however, becoming progressively more difficult to maintain that frontal cats show relatively mild defects on DR because
Table 1

Performance on Delayed Response Task

\begin{tabular}{|c|c|c|c|c|c|c|c|c|}
\hline \multirow[b]{3}{*}{ Cat } & \multicolumn{8}{|c|}{ Phase } \\
\hline & \multicolumn{2}{|c|}{ Predelay } & \multicolumn{2}{|c|}{0} & \multicolumn{2}{|c|}{5} & \multicolumn{2}{|c|}{15} \\
\hline & Errors & Trials & Errors & Trials & Errors & Trials & Errors & Trials \\
\hline Kanga & 15 & 45 & 2 & 10 & 41 & $100^{*}$ & - & - \\
\hline Bobette & 0 & 0 & 17 & 50 & 47 & $100^{*}$ & - & - \\
\hline Jeremy & 22 & 82 & 3 & 10 & 32 & 120 & 39 & $100^{*}$ \\
\hline Alex & 21 & 61 & 0 & 0 & 45 & $100^{*}$ & 一 & $\ldots$ \\
\hline Wob & 4 & 24 & 2 & 10 & 31 & 70 & 39 & $100^{*}$ \\
\hline Sonny & 34 & 104 & 0 & 0 & 30 & $100^{*}$ & - & - \\
\hline Octavia & 0 & 0 & 0 & 0 & 17 & 60 & 51 & $100^{*}$ \\
\hline Imp & 16 & 66 & 0 & 0 & 40 & $100^{*}$ & - & - \\
\hline Frontal Median & 15 & 53 & 1 & 5 & - & - & - & - \\
\hline Devi & 0 & 0 & 0 & 0 & 29 & $100 *$ & - & - \\
\hline Edwin & 0 & 0 & 0 & 0 & 0 & 0 & 4 & 20 \\
\hline Fay & 0 & 0 & 0 & 0 & 0 & 0 & 0 & 0 \\
\hline Isabelle & 32 & 122 & 0 & 0 & 17 & 50 & 10 & 60 \\
\hline Jean & 0 & 0 & 0 & 0 & 20 & 50 & 4 & 30 \\
\hline Kirk & 6 & 26 & 0 & 0 & 21 & 80 & 25 & $100^{*}$ \\
\hline Leibniz & 0 & 0 & 0 & 0 & 7 & 20 & 14 & 60 \\
\hline Lou & 8 & 28 & 0 & 0 & 30 & 80 & 20 & 70 \\
\hline Nan & 41 & 151 & 0 & 0 & 28 & 120 & 0 & 0 \\
\hline Ned & 14 & 44 & 2 & 10 & 33 & 80 & 0 & 0 \\
\hline Rebecca & 20 & 90 & 0 & 0 & 19 & $100^{*}$ & - & - \\
\hline Ruth & 16 & 66 & 7 & 30 & 25 & 100 & 43 & $100^{*}$ \\
\hline Control Median & 7 & 27 & 0 & 0 & 20 & 80 & 7 & 45 \\
\hline 37 Alley Cats (Divac, & 1968,1 & $969)$ & & & & & & \\
\hline Median & 0 & 0 & 0 & 0 & $\mathbf{0}$ & 0 & 0 & 0 \\
\hline Maximum & 0 & 0 & 1 & 10 & 4 & 10 & 13 & 60 \\
\hline
\end{tabular}

*Failed 
have been obtained from carnivores. Dogs reared in small cages are inferior to littermates reared as pets in DR learning (Thompson \& Heron, 1954). Cats reared in the laboratory average three to four times as many errors on the Hebb-Williams maze as animals secured as adults (Warren, 1965). Both dogs (Thompson \& Heron, 1954) and cats (Wilson, Warren, \& Abbott, 1965) reared from birth in small cages are impaired in detour learning when compared with littermates reared under less restricted conditions.

Although it is questionable whether cage-rearing results in general intellectual impairment in experimental animals (Gluck \& Harlow, 1971; Harlow, Harlow, Schlitz, \& Mohr, 1971), the results of the present experiment indicate that cage-reared controls may provide a gross underestimate of normal performance on tests with an important spatial orientation component, thereby perhaps obscuring or attenuating the possible lesion effects.

\section{REFERENCES}

DIVAC, I. Effects of prefrontal and caudate lesions on delayed response in cats. Acta
Biologiae Experimentalis (Warsaw), 1968, $26,149-167$

DIVAC, I. Delayed reponse in blind cats before and after prefrontal ablation. Physiology \& Behavior, 1969, 4, 795-799.

DIVAC, I. Delayed alternation in cats with lesions of the prefrontal cortex and the caudate nucleus. Physiology \& Behavior, in press.

DIVAC. I.. \& WARREN, J. M. Delayed response by frontal monkeys in the Nencki Testing Situation. Neuropsychologia, 1971, 9, 209-217.

FINAN, J. L. Delayed response with predelay reinforcement in monkeys after removal of the frontal lobes. American Journal of Psychology, 1942, 55, 202-214.

GLUCK, J. P., \& HARLOW, H. F. The effects of deprived and enriched rearing conditions on later learning: A review. In L. E. Jarrard (Ed.), Cognitive processes of nonhuman primates. $\mathrm{N}$ ew York: Academic Press, 1971. Pp. 103-119.

HARLOW, H. F., HARLOW, M. K., SCHLITZ, K. A., \& MOHR, D. J. The effect of early adverse and enriched environments on the learning ability of rhesus monkeys. In L. E. Jarrard (Ed.), Cognitive processes of nonhuman primates. New York: Academic Press, 1971. Pp. 121-148.

JASPER, H. H., \& AJMONE-M ARSAN, C. A stereotoxic atlas of the diencephalon of the cat. Ottawa: National Research Council of Canada, 1960.

LAWICKA, W.. \& KONORSKI, J. The effects of prefrontal lobectomies on the delayed responses of cats. Acta Biologiae Experimentalis (Warsaw), 1961, 21,
141-156.

PINSKER, H., \& FRENCH, G. Indirect delayed reaction under various testing conditions in normal and midlateral frontal monkeys. Neuropsychologia, $1967,5,13-24$

STAMM, J. S. Dorsolateral frontal ablations and response processes in monkeys Joumal of Comparative \& Physiological Psychology, 1970, 70, 437-447.

THOMPSON, V. E. Neonatal orbitofrontal lobectomies and delayed response behavior in cats. Physiology \& Behavior, $1968,3,631-635$.

THOMPSON, W. R, \& HERON, w. The effects of restricting early experience on the problem-solving capacity of dogs. Canadian Journal of Psychology, 1954, 8 , 17-31.

WARREN, J. M. The behavior of carnivores and primates with lesions in the prefrontal cortex. In J. M. Warren \& $\mathrm{K}$. Akert (Eds.), The frontal granular cortex and behavior. New York: McGraw-Hill, 1964. Pp. 168-191.

WARREN, J, M. Primate leaming in comparative perspective. In A. M. Schrier, H. F. Harlow, and F. Stollnitz (Eds.), Behavior of nonhuman primates. New York: Academic Press, 1965 Pp. 249-281.

WARREN, J. M., WARREN, H. B., \& AKERT, K. Orbito-frontal cortical lesions and learning in cats. Journal of Comparative Neurology, 1962, 118, 17-41.

WILSON, M., WARREN, J. M., \& ABBOTT $\mathrm{L}$. Infantile stimulation, activity, and learning by cats. Child Development. $1965,36,843-853$. 